\title{
Elderly patients with atrial fibrillation
} in routine clinical practice-peri-procedural management of edoxaban oral anticoagulation therapy is associated with a low risk of bleeding and thromboembolic complications: a subset analysis of the prospective, observational, multinational EMIT-AF study

M. Unverdorben ${ }^{1 *}\left(\mathbb{D}\right.$, C. von Heymann², A. Santamaria ${ }^{3}$, M. Saxena ${ }^{4}$, T. Vanassche ${ }^{5}$, J. Jin ${ }^{1}$, P. Laeis ${ }^{6}$, R. Wilkins ${ }^{7}$, C. Chen ${ }^{1}$ and P. Colonna ${ }^{8}$

\begin{abstract}
Background: Annually $>10 \%$ of patients with atrial fibrillation on oral anticoagulation undergo invasive procedures. Optimal peri-procedural management of anticoagulation, as judged by major bleeding and thromboembolic events, especially in the elderly, is still debated.

Methods: Procedures from 1442 patients were evaluated. Peri-procedural edoxaban management was guided only by the experience of the attending physician. The primary safety outcome was the rate of major bleeding. Secondary outcomes included the peri-procedural administration of edoxaban, other bleeding events, and the main efficacy outcome, a composite of acute coronary syndrome, non-hemorrhagic stroke, transient ischemic attack, systemic embolic events, deep vein thrombosis, pulmonary embolism, and mortality.

Results: Of the 1442 patients, 280 (19\%) were <65, 550 (38\%) were 65-74, 514 (36\%) 75-84, and 98 (7\%) were 85 years old or older. With increasing age, comorbidities and risk scores were higher. Any bleeding complications were uncommon across all ages, ranging from $3.9 \%$ in patients $<65$ to $4.1 \%$ in those 85 years or older; major bleeding rates in any age group were $\leq 0.6 \%$. Interruption rates and duration increased with advancing age. Thromboembolic events were more common in the elderly, with all nine events occurring in those $>65$, and seven in patients aged $>75$ years.
\end{abstract}

\footnotetext{
*Correspondence: munverdorben@dsi.com

${ }^{1}$ Global Medical Affairs Specialty and Value Products, Daiichi Sankyo Inc. 211 Mt Airy Road, Basking Ridge, NJ 07920, USA

Full list of author information is available at the end of the article

The authors identified an error in Table 1 related to two values on EHRA bleeding risk-low row

Portions of this data had been accepted as a poster presentation by EHRA at the now-cancelled EHRA 2020 Congress
} give appropriate credit to the original author(s) and the source, provide a link to the Creative Commons licence, and indicate if changes were made. The images or other third party material in this article are included in the article's Creative Commons licence, unless indicated otherwise in a credit line to the material. If material is not included in the article's Creative Commons licence and your intended use is not permitted by statutory regulation or exceeds the permitted use, you will need to obtain permission directly from the copyright holder. To view a copy of this licence, visit http://creativecommons.org/licenses/by/4.0/. The Creative Commons Public Domain Dedication waiver (http://creativecommons.org/publicdomain/zero/1.0/) applies to the data made available in this article, unless otherwise stated in a credit line to the data. 
Conclusion: Despite increased bleeding risk factors in the elderly, bleeding rates were small and similar across all age groups. However, there was a trend toward more thromboembolic complications with advancing age. Further efforts to identify the optimal management to reduce ischemic complications are needed.

Trial registration: NCT\# 02950168, October 31, 2016

Keywords: Age, Bleeding, Systemic thromboembolism, Atrial fibrillation, Edoxaban

\section{Background}

Aging is associated with a decline of many physiologic functions, determined by factors that include genetic predisposition, environmental influences, and lifestyle choices. However, there is considerable variation in the impact of aging on individual responses to disease [1]. In cardiovascular medicine, the number and severity of risk factors increases in the elderly, leading to a higher incidence of diseases such as atrial fibrillation (AF), along with sequelae such as systemic thromboembolism and stroke [2]. The interaction of the body with therapeutic measures changes too, as reflected by altered pharmacokinetics and pharmacodynamics [3], associated with changes in glomerular filtration rate, decreased protein binding and decrease in liver function. Therefore, in therapies that cover a wide range of ages, it is prudent to investigate the benefits and risks stratified by age groups [4].

Based on US data from 2002 [5], an adult undergoes an average of approximately nine surgical procedures in a lifetime, with a rate that increases with age, reaching a rate of 0.16 operations/person/year at age 75 . With over 33 million patients with AF (2010 data) globally [6], there is a large population at need of oral anticoagulation in atrial fibrillation to reduce the risk of thromboembolic events.

An estimated $10 \%$ of patients treated with oral anticoagulants are annually subjected to diagnostic or therapeutic procedures [7] of varying invasiveness and, thus, to the risk of severe bleeding and ischemic events [8]. All procedures with a bleeding risk require optimization of the peri-procedural management of anticoagulation: whether to interrupt oral anticoagulation at all and if so, for how long and when, relative to the procedure. As patients of advanced age, especially the very elderly aged 85 years and above [9] are often undertreated with oral anticoagulants because of concerns with regard to increased bleeding risk, and lack of benefit in stroke prevention $[10,11]$. It is valuable to understand whether older patients are also treated differently peri-procedurally from younger patients.

The EMIT (Edoxaban Management in Diagnostic and Therapeutic Procedures) study [12] prospectively investigated the peri-procedural management and outcome in a large cohort of unselected patients who were treated with the direct oral anticoagulant edoxaban for any of its approved indications. Adding to the EMIT results, this paper discusses the safety and efficacy of edoxaban in elderly patients from those aged $\geq 65$ years of age to the very elderly, aged 85 years. Although the majority of patients with AF are elderly, and so typical patient management might be assumed to meet the needs of the elderly, a detailed cohort analysis allows understanding of when, as aging progresses, differences in risk and tactics for treatment and risk mitigation become identifiable.

\section{Methods \\ Design}

The EMIT study was a multicentre, prospective, and noninterventional study integrating data from seven European and four Asian countries. The detailed design has been published [13, 14]. The study was conducted in accordance with the Declaration of Helsinki and with local Institutional Review Board approvals and was registered as NCT02950168. Written informed consent was obtained from participants prior to enrolment. The periprocedural management of anticoagulant therapy was at the discretion of the investigator, including any decision whether to interrupt edoxaban therapy and the timing/duration of any interruption. No attempt was made to influence patient management by the study authors, study team or the sponsor.

\section{Objectives and outcome parameters}

The objective of the registry was to analyse the periprocedural management of patients receiving edoxaban in daily practice and to collect data on safety and other outcome parameters in these patients. The primary safety outcome was the rate of major bleeding (MB) from five days prior to the procedure to 30 days post-procedure using the International Society of Thrombosis and Haemostasis (ISTH) definition [15].

Secondary outcomes included exploration of the main efficacy outcome, defined as the composite of acute coronary syndrome (ACS), stroke, transient ischemic attack (TIA), systemic embolic events (SEE), deep vein thrombosis (DVT), pulmonary embolism (PE), and cardiovascular $(\mathrm{CV})$ mortality, along with the individual components. Other secondary outcomes included the incidences of clinically relevant non-major bleeding 
(CRNMB) and all-cause mortality. CRNMB events were defined as overt bleeding that required medical attention but that did not fulfil the criteria for MB. Other secondary outcomes of the study were evaluation of the peri-procedural interruption and dosing of edoxaban. All incidents of MB, CRNMB, ACS, and acute thromboembolic events were reviewed and unanimously adjudicated by the Steering Committee. Bleeding had to commence during or after the procedure to be classified as a procedural complication.

\section{Patient recruitment}

Enrolment commenced in December 2016. Subjects were recruited consecutively. Eligible patients were $\geq 18$ years of age, had AF, were treated with edoxaban according to the local labels, were not enrolled in any other study concurrently, and underwent any type of diagnostic or therapeutic procedure. Data from the first procedure in each patient is reported.

\section{Observations}

The observation period of the study started five days before the procedure and ended 30 days afterward. Date of visit, details of edoxaban treatment, and clinical outcomes were documented at 30 days after each procedure. No interruption of edoxaban therapy was defined if edoxaban was administered on each day of the observation period. Any interruption of edoxaban treatment was recorded as the number of days without administration of edoxaban, pre-procedural and/or post-procedural. Any dose skipped before or on the day of the procedure was defined as pre-procedural.

Peri-procedural EHRA bleeding risk [16]; HAS-BLED [17] (Hypertension, Abnormal renal/liver function, Stroke, Bleeding history or predisposition, Labile international normalized ratio, Elderly, Drugs/alcohol concomitantly) score; $\mathrm{CHA}_{2} \mathrm{DS}_{2}$-VASc (Congestive heart failure, Hypertension, Age $\geq 75$ [doubled], Diabetes, Stroke [doubled]-Vascular disease, Age 65-74 years, and gender [female]) score [18]; details of edoxaban treatment; diagnostic/therapeutic procedures; and clinical findings were documented at baseline and during the peri-procedural period.

\section{Statistical analysis}

Binary, categorical, and ordinal parameters were summarized by means of absolute and percentage numbers. Numerical data were described by standard statistics. The statistical analyses were performed using $\operatorname{SAS}^{\circledR}$ version 9.3 or higher (SAS Institute, Cary, North Carolina, USA).

In order to maximize the utility of the data, three sets of age cut-offs were utilized: less than 65 years versus 65 years and older; less than 75 years versus 75 years and older; a more granular set of four groups with $<65, \geq 65$ to $<75, \geq 75$ to $<85$, and $\geq 85$ years following UN standards [19]; and in line with the FDA [20], a second cut-off of 75 years and above was chosen. These multiple cut-offs permit analysis following both conventional definitions of the elderly and very elderly, as well as acknowledging that many populations are reaching advanced age in a healthier state than previous generations [21]. Use of multiple narrow cohorts, plus their larger combinations, permits analysis whatever definition of the elderly is chosen.

\section{Results}

The dataset included 1,442 patients' first procedures. Of these patients, 280 (19\%) were younger than 65 years, 550 (38\%) were 65-74 years old, 514 (36\%) 75-84 years old, and 98 (7\%) were 85 years old or older. See Fig. 1.

In all age groups except those $\geq 85$ years, the patients were predominantly male with the male proportion declining with age. All recorded comorbidities were more prevalent with increasing age, except obesity/overweight (assessed as BMI [22]) and dyslipidaemia, which trended lower in patients aged 85 years and older. A creatinine clearance of $\leq 50 \mathrm{~mL} / \mathrm{min}$ was found in $21 \%$ of patients aged from 75 to 85 years, and $49 \%$ of patients of 85 years or older. Use of the $30 \mathrm{mg}$ edoxaban dose increased with age, being utilized in $9 \%$ of patients $<65$ years, and in $68 \%$ of patients $\geq 85$ years. Heparin bridging was used in about $10 \%$ of patients, with a slight trend toward greater use in the more elderly. HAS-BLED and $\mathrm{CHA}_{2} \mathrm{DS}_{2}$-VASc scores also increased with age, particularly in the over 75 age groups, (although it should be noted that age is a component of each score). Clinical characteristics and patient baseline data summarized in Table 1 were included as predictors of the composite event of major or CRNM bleeding, all cause mortality, stroke, SEE, ACS, VTE, and TIA in a logistic regression analysis. Due to likely correlations among predictors, a stepwise approach is applied. A significance level of 0.1 was set to allow a variable into the model and for a variable to stay in the model. The final selected model includes predictors of weight $(\mathrm{p}=0.003)$, prior coronary heart disease $(\mathrm{p}=0.029)$, prior use of heparin $(\mathrm{p}=0.043)$, and prior use of P-gp inhibitors $(\mathrm{p}=0.054)$. Weight, prior coronary heart disease, and prior use of heparin emerged as independent predictors. Low body weight, prior coronary heart disease, and prior heparin use are associated with higher event probability. Importantly, age was not an identified predictor of adverse outcomes.

The demographic and medical backgrounds of the evaluated patients are summarized in Table 1 . 


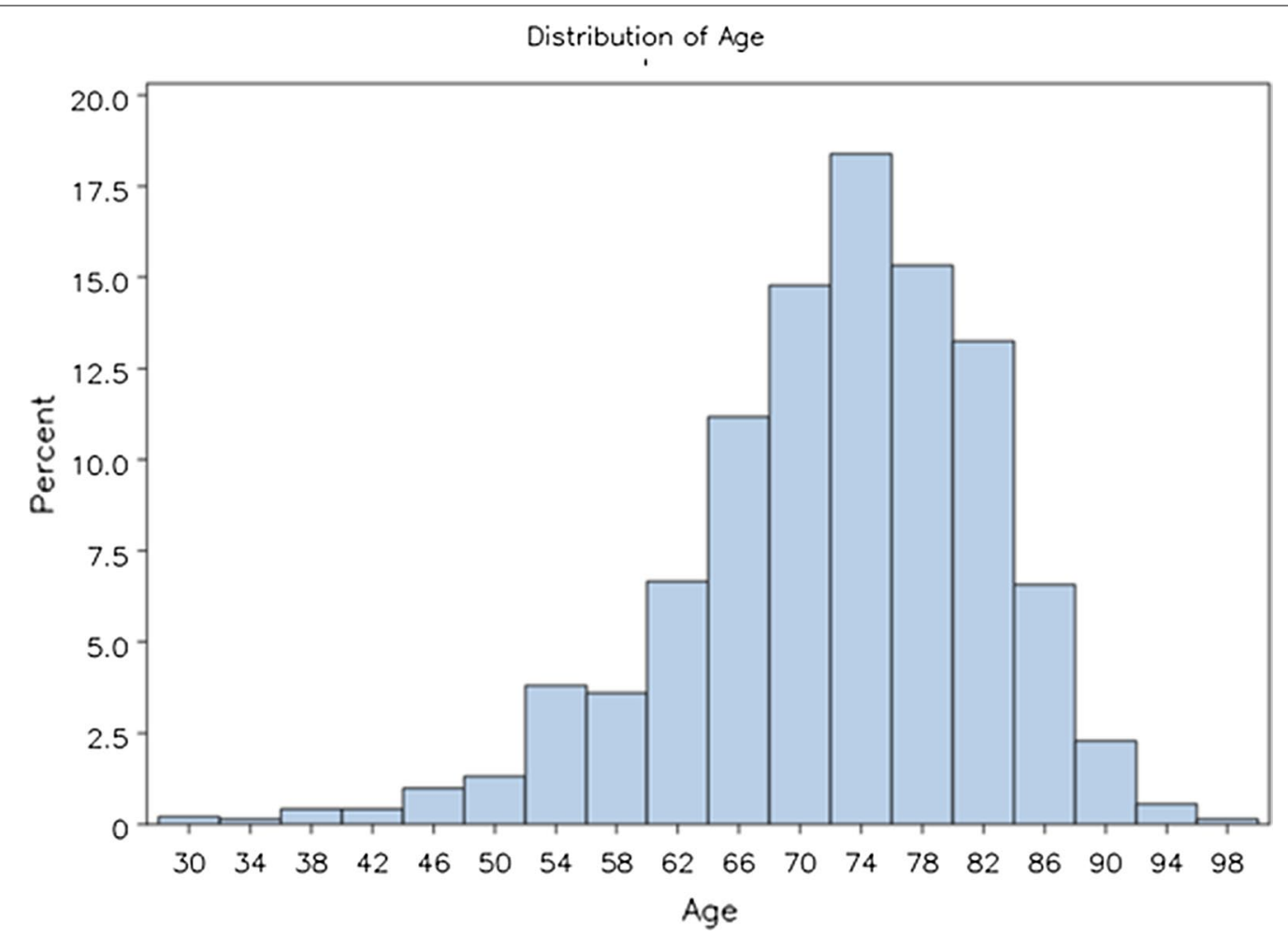

Fig. 1 Age distribution of study population

Table 1 Patient background information

\begin{tabular}{|c|c|c|c|c|c|c|c|}
\hline Age group (years) & $<65$ & $\geq 65$ & $<75$ & $\geq 75$ & $\geq 65$ to $<75$ & $\geq 75$ to $<85$ & $\geq 85$ \\
\hline \# of subjects & 280 & 1162 & 830 & 612 & 550 & 514 & 98 \\
\hline Age mean (SD) & $56.5(7.2)$ & $75.5(6.4)$ & $65.4(8.0)$ & $80.5(4.2)$ & $69.9(2.9)$ & $79.1(2.8)$ & $87.8(2.8)$ \\
\hline Male n (\%) & $206(73.6)$ & $715(61.5)$ & $593(71.4)$ & $328(53.6)$ & $387(70.4)$ & $281(54.7)$ & $47(48.0)$ \\
\hline BMI mean (SD) & $28.8(5.4)$ & $27.1(4.7)$ & $28.2(5.1)$ & $26.5(4.5)$ & $27.8(4.8)$ & $26.7(4.6)$ & $25.6(3.9)$ \\
\hline Hypertension n (\%) & $161(57.5)$ & $893(76.9)$ & $568(68.4)$ & $486(79.4)$ & $407(74.0)$ & $405(78.8)$ & $81(82.7)$ \\
\hline Dyslipidaemia n (\%) & $74(26.4)$ & $535(46.0)$ & $333(40.1)$ & $276(45.1)$ & $259(47.1)$ & $241(46.9)$ & $35(35.7)$ \\
\hline Diabetes mellitus n (\%) & $51(18.2)$ & $304(26.2)$ & $188(22.7)$ & $167(27.3)$ & $137(24.9)$ & $140(27.2)$ & $27(27.6)$ \\
\hline Coronary heart disease n (\%) & $30(10.7)$ & $272(23.4)$ & $144(17.3)$ & $158(25.8)$ & $114(20.7)$ & $135(26.3)$ & $23(23.5)$ \\
\hline Valvular heart disease n (\%) & $33(11.8)$ & $229(19.7)$ & $131(15.8)$ & $131(21.4)$ & $98(17.8)$ & $110(21.4)$ & $21(21.4)$ \\
\hline $\mathrm{CrCl}$ mean $(\mathrm{SD})$ & $104.5(37.1)$ & $67.0(24.4)$ & $86.2(31.6)$ & $57.3(19.7)$ & $77.8(24.5)$ & $59.7(19.2)$ & 44.7 (17.9) \\
\hline $\mathrm{CrCL} \leq 50 \mathrm{~mL} / \mathrm{min} \mathrm{n}(\%)$ & $1(0.4)$ & $179(15.4)$ & $25(3.0)$ & $155(25.3)$ & $24(4.4)$ & $107(20.8)$ & $48(49.0)$ \\
\hline $\mathrm{CHA}_{2} \mathrm{DS}_{2}$-VASc score mean (SD) & $1.5(1.1)$ & $3.5(1.4)$ & $2.4(1.3)$ & $4.2(1.3)$ & $2.8(1.2)$ & $4.2(1.3)$ & $4.4(1.2)$ \\
\hline HAS-BLED score mean (SD) & $0.9(0.9)$ & $2.0(1.0)$ & $1.6(1.0)$ & $2.1(1.0)$ & $1.9(0.9)$ & $2.1(1.0)$ & $2.1(1.0)$ \\
\hline EHRA bleeding risk-minor n (\%) & $36(12.9)$ & $263(22.6)$ & $147(17.7)$ & $152(24.8)$ & $111(20.2)$ & $124(24.1)$ & $28(28.6)$ \\
\hline EHRA bleeding risk-low n (\%) & $174(62.1)$ & $580(49.9)$ & $457(55.1)$ & $297(48.5)$ & $283(51.5)$ & $252(49.0)$ & $45(45.9)$ \\
\hline EHRA bleeding risk-high n (\%) & $62(22.1)$ & $289(24.9)$ & $199(24.0)$ & $152(24.8)$ & $137(24.9)$ & $129(25.1)$ & $23(23.5)$ \\
\hline EHRA risk unknown n (\%) & $8(2.9)$ & $30(2.6)$ & $27(3.3)$ & $11(1.8)$ & $19(3.5)$ & $9(1.7)$ & $2(2.0)$ \\
\hline 30 mg daily edoxaban dose n (\%) & $25(8.9)$ & $341(29.3)$ & $126(15.2)$ & $240(39.2)$ & $101(18.4)$ & $173(33.7)$ & $67(68.4)$ \\
\hline $\begin{array}{l}\text { Heparin "bridging" } \\
\text { n (\%) }\end{array}$ & $134(9.3)$ & $113(9.7)$ & 71 (8.6) & (10.3) & $50(9.1)$ & $51(9.9)$ & $12(12.2)$ \\
\hline
\end{tabular}

All data presented as mean $\pm S D$; number (\%); or number, mean $\pm S D$ 
EHRA procedural bleeding risk distribution was similar across all age groups, although the proportion of minor risk procedures increased in older age groups.

In all patient age groups, vascular access and transcatheter diagnostics or interventions were the most frequently performed procedures. The next three most common procedures across all age groups were cardiovascular/vascular, gastroenterological, and dentistry procedures. Orthopaedic and ophthalmologic procedures were more common in those aged 75 years or more. See Table 2 for further details. Of 1,442 first procedures, 1,324 (92\%) were pre-scheduled.

Edoxaban was discontinued pre-procedurally in $48 \%$ of all patients. Interruption rates were higher and duration of interruption longer in the older age groups. See Table 3 for details. Most patients aged 65 years or more had a post-procedural therapy interruption. Interruptions of two or more days were more common in patients aged 65 years or older $(\mathrm{p}<0.001)$. Figure 3 shows the number of patients in each age group taking edoxaban on each peri-procedural day.

Bleeding occurred in $3.9 \%$ of patients $<65$ years and $4.1 \%$ in those 85 years or older. Major bleeding and CRNMB had an overall incidence of $1.0 \%$, with the highest incidence in patients aged 65-74 years (1.6\%). There was no discernible relationship between age and all bleeding complications. However, ischemic/thromboembolic complications were more common in the elderly, with all of nine events occurring in those over 65 years, and seven $(77.8 \%)$ in those patients of 75 years and older. See Table 4 for details.

\section{Discussion}

We report the impact of age on the management and incidence of critical thromboembolic and bleeding events in patients with AF treated with the direct oral anticoagulant edoxaban. While bleeding rates were low, thromboembolic rates were higher in the elderly. This study complements the PAUSE and DRESDEN studies $[8,23]$, by describing outcomes associated with edoxaban administration, and describing use in a routine clinical practice setting, and provides additional data on the impact of age on outcome.

Data was collected, in the first prospective observational multicentre multinational study on the management and outcomes of edoxaban therapy, on 1442 unselected procedures in AF patients. All common comorbidities increased with age, except for obesity and dyslipidaemia, which were lower in patients 85 years and older. Of those patients aged from 75 to 85 years, $21 \%$ had a creatinine clearance of $\leq 50 \mathrm{~mL} / \mathrm{min} ; 49 \%$ of patients 85 years or older had a creatinine clearance of $\leq 50 \mathrm{~mL} / \mathrm{min}$. Use of $30 \mathrm{mg}$ edoxaban dose was more common in the older age groups, being taken by $9 \%$ of patients $<65$ years, and $68 \%$ of patients at least 85 years of age. HAS-BLED and $\mathrm{CHA}_{2} \mathrm{DS}_{2}$-VASc scores also increased with age (although of note age is a component of each score). Overall, and as expected [11, 24], in older patients the ischemic cardiovascular risk was more clinically significant than the bleeding risk. Despite detailed analysis (Table 1) across multiple age cohort groups, no other factors linked to age were identified. This data supports the case that, if dose is appropriately adjusted based

Table 2 Procedure groups by age range

\begin{tabular}{|c|c|c|c|c|c|c|c|c|}
\hline $\begin{array}{l}\text { Age (years) } \\
\text { Procedure type }\end{array}$ & $\leq 65$ & $\geq 65$ & $\leq 75$ & $\geq 75$ & $\geq 65$ to $<75$ & $\geq 75$ to $<85$ & $\geq 85$ & Total \\
\hline N & 280 & 1162 & 830 & 612 & 550 & 514 & 98 & 1442 \\
\hline Cardiothoracic and vascular surgery & $27(9.6 \%)$ & $160(13.8 \%)$ & $85(10.2 \%)$ & $102(16.7 \%)$ & $58(10.6 \%)$ & $80(15.6 \%)$ & $22(22.5 \%)$ & $187(13.0 \%)$ \\
\hline Dentistry & $22(7.9 \%)$ & $121(10.4 \%)$ & $79(9.5 \%)$ & $64(10.5 \%)$ & $57(10.4 \%)$ & $51(9.9 \%)$ & $13(13.3 \%)$ & $143(9.9 \%)$ \\
\hline Dermatology & $4(1.4 \%)$ & $44(3.8 \%)$ & $21(2.5 \%)$ & $27(4.4 \%)$ & $17(3.1 \%)$ & $19(3.7 \%)$ & $8(8.2 \%)$ & $48(3.3 \%)$ \\
\hline Ear, nose, throat & $1(0.4 \%)$ & $14(1.2 \%)$ & $10(1.2 \%)$ & $5(0.8 \%)$ & $9(1.6 \%)$ & $4(0.8 \%)$ & $1(1.1 \%)$ & $15(1.0 \%)$ \\
\hline Gastroenterology & $24(8.6 \%)$ & $150(12.9 \%)$ & $105(12.7 \%)$ & $69(11.3 \%)$ & $81(14.7 \%)$ & $60(11.7 \%)$ & $9(9.2 \%)$ & $174(12.1 \%)$ \\
\hline Gynaecology & $3(1.1 \%)$ & $10(0.9 \%)$ & $6(0.7 \%)$ & $7(1.1 \%)$ & $3(0.6 \%)$ & $5(1.0 \%)$ & $2(2.0 \%)$ & 13 (0.9\%) \\
\hline Haematology & 0 & $2(0.2 \%)$ & $1(0.1 \%)$ & $1(0.2 \%)$ & $1(0.2 \%)$ & $1(0.2 \%)$ & 0 & $2(0.2 \%)$ \\
\hline Miscellaneous & $5(1.8 \%)$ & $8(0.7 \%)$ & $11(1.3 \%)$ & $2(0.3 \%)$ & $6(1.1 \%)$ & $1(0.2 \%)$ & $1(1.0 \%)$ & $13(0.9 \%)$ \\
\hline Ophthalmology & $5(1.8 \%)$ & $70(6.0 \%)$ & $27(3.3 \%)$ & 48 (7.8\%) & $22(4.0 \%)$ & $43(8.4 \%)$ & $5(5.1 \%)$ & 75 (5.2\%) \\
\hline Orthopaedic & $7(2.5 \%)$ & 87 (7.5\%) & $38(4.6 \%)$ & $56(9.1 \%)$ & $31(5.6 \%)$ & 46 (9.0\%) & $10(10.2 \%)$ & $94(6.5 \%)$ \\
\hline Surgery (general) & $12(4.3 \%)$ & $59(5.1 \%)$ & $40(4.8 \%)$ & $31(5.1 \%)$ & $28(5.1 \%)$ & $26(5.0 \%)$ & $5(5.1 \%)$ & 71 (4.9\%) \\
\hline Urology & $3(1.1 \%)$ & $58(5.0 \%)$ & 32 (3.9\%) & $29(4.7 \%)$ & $29(5.3 \%)$ & 25 (4.9\%) & $4(4.1 \%)$ & $61(4.2 \%)$ \\
\hline $\begin{array}{l}\text { Vascular access and transcatheter } \\
\text { diagnostics and interventions }\end{array}$ & 167 (59.6\%) & 379 (32.6\%) & 375 (45.2\%) & 171 (27.9\%) & 208 (37.8\%) & 153 (29.8\%) & $18(18.4 \%)$ & $546(37.9 \%)$ \\
\hline
\end{tabular}


Table 3 Interruption characteristics by age group

\begin{tabular}{|c|c|c|c|c|}
\hline Age (years) & $\mathrm{N}$ & No interruption & 1 day interruption & $\geq 2$ days interruption \\
\hline \multicolumn{5}{|c|}{ Pre-procedural interuption duration } \\
\hline$<65$ & 279 & $145(52.0 \%)$ & $54(19.4 \%)$ & $80(28.7 \%)$ \\
\hline$\geq 65$ & 1161 & $422(36.3 \%)$ & $320(27.6 \%)$ & $419(36.1 \%)$ \\
\hline$<75$ & 828 & $365(44.1 \%)$ & $206(24.9 \%)$ & $257(31.0 \%)$ \\
\hline$\geq 75$ & 612 & $202(33.0 \%)$ & $168(27.5 \%)$ & $242(39.5 \%)$ \\
\hline$\geq 65-<75$ & 549 & $220(40.1 \%)$ & $152(27.7 \%)$ & $177(32.2 \%)$ \\
\hline$\geq 75-<85$ & 514 & $178(34.6 \%)$ & $138(26.8 \%)$ & $198(38.5 \%)$ \\
\hline$\geq 85$ & 98 & $24(24.5 \%)$ & $30(30.6 \%)$ & $44(44.9 \%)$ \\
\hline \multicolumn{5}{|c|}{ Post-procedural interuption duration } \\
\hline$<65$ & 279 & $226(81.0 \%)$ & $19(6.8 \%)$ & $34(12.2 \%)$ \\
\hline$\geq 65$ & 1157 & $810(70.0 \%)$ & $93(8.0 \%)$ & $254(22.0 \%)$ \\
\hline$<75$ & 825 & $621(75.3 \%)$ & $56(6.8 \%)$ & $148(17.9 \%)$ \\
\hline$\geq 75$ & 611 & $415(67.9 \%)$ & $56(9.2 \%)$ & $140(22.9 \%)$ \\
\hline$\geq 65-<75$ & 546 & $395(72.3 \%)$ & $37(6.8 \%)$ & $114(20.9 \%)$ \\
\hline$\geq 75-<85$ & 514 & $351(68.3 \%)$ & $50(9.7 \%)$ & $113(22.0 \%)$ \\
\hline$\geq 85$ & 97 & $64(66.0 \%)$ & $6(6.2 \%)$ & $27(27.8 \%)$ \\
\hline \multicolumn{5}{|c|}{ Interuption incidence } \\
\hline$<65$ & 279 & $134(48.0 \%)$ & $92(33.0 \%)$ & $11(3.9 \%)$ \\
\hline $65-74$ & 549 & $194(35.3 \%)$ & $201(36.6 \%)$ & $26(4.7 \%)$ \\
\hline $75-84$ & 514 & $158(30.7 \%)$ & $193(37.5 \%)$ & $20(3.9 \%)$ \\
\hline$\geq 85$ & 98 & $21(21.4 \%)$ & $43(43.9 \%)$ & $3(3.1 \%)$ \\
\hline$\geq 65$ & 1161 & $373(32.1 \%)$ & $437(37.6 \%)$ & $49(4.2 \%)$ \\
\hline$<75$ & 828 & $328(39.6 \%)$ & $293(35.4 \%)$ & $37(4.5 \%)$ \\
\hline$\geq 75$ & 612 & $179(29.2 \%)$ & $236(38.6 \%)$ & $23(3.8 \%)$ \\
\hline
\end{tabular}

upon label requirements, elderly patients do not require modification of management.

Edoxaban interruption rates and duration of interruption increased with age. The difference in postprocedural interruption across age groups ( $>2$-day post-procedural interruption $12.2 \%$ in patients $<65$ vs. $27.8 \%$ in patients $\geq 85$ years), suggests physicians tend to be cautious in resuming edoxaban in older patients.

Any bleeding complications were rare across all ages. Major bleeding (0.4\%), and CRNMB had a combined incidence of $1.0 \%$, with the highest incidence in patients aged $65-74$ years (1.6\%). There was no discernible relationship between age and bleeding complications. Ischemic or thromboembolic complications were, however, more common in the elderly.

Patients aged 65 years and above had combined rates of $\mathrm{MB}$ and $\mathrm{CRNMB}$ only slightly higher than those $<65$ years $(1.1 \%$ vs. $0.7 \%)$ but more ischemic/ thromboembolic events $(0.8 \%$ vs. $0 \%)$. Possible explanations include procedures with a higher EHRA bleeding risk being performed in the advanced age groups; or differences in the interruption of edoxaban; or age as an independent risk factor per se. EHRA risk category is an unlikely explanation in patients of 65 years and above as this factor is only slightly more prevalent than in younger individuals: indeed EHRA minor risk procedures were more common in the elderly (see Fig. 2). A more likely explanation is the duration of peri-procedural interruption of edoxaban therapy, which shows a trend toward increased duration with age and appears to be independent from the EHRA bleeding risk. Longer interruption of edoxaban therapy with the intent to reduce bleeding appears to come at the cost of increased risk of thromboembolic/ischemic events. The increase in thromboembolic rates across the age groups was from zero events under age 65 to nine events in the 65-and-older group, while in the same groups the $\mathrm{MB} / \mathrm{CRNMB}$ rate differed by only $0.4 \%(0.7 \%$ to $1.1 \%)$. Prolonged interruption of therapy in the elderly is not associated with a lower risk of major bleeding, but appears to be associated with a higher thromboembolic risk. Other studies have evaluated peri-procedural risk $[8,23,25]$ but have not provided results stratified by age. The PAUSE study [8], which included 3007 procedures, reported post-procedural rates of $\mathrm{MB}$ of $1.35 \%$ for apixaban, $0.90 \%$ for dabigatran, and $1.85 \%$ for rivaroxaban cohorts with arterial thromboembolism occurring in $0.16 \%, 0.6 \%$, and $0.37 \%$, respectively. RE-LY [25] reported a thromboembolism 


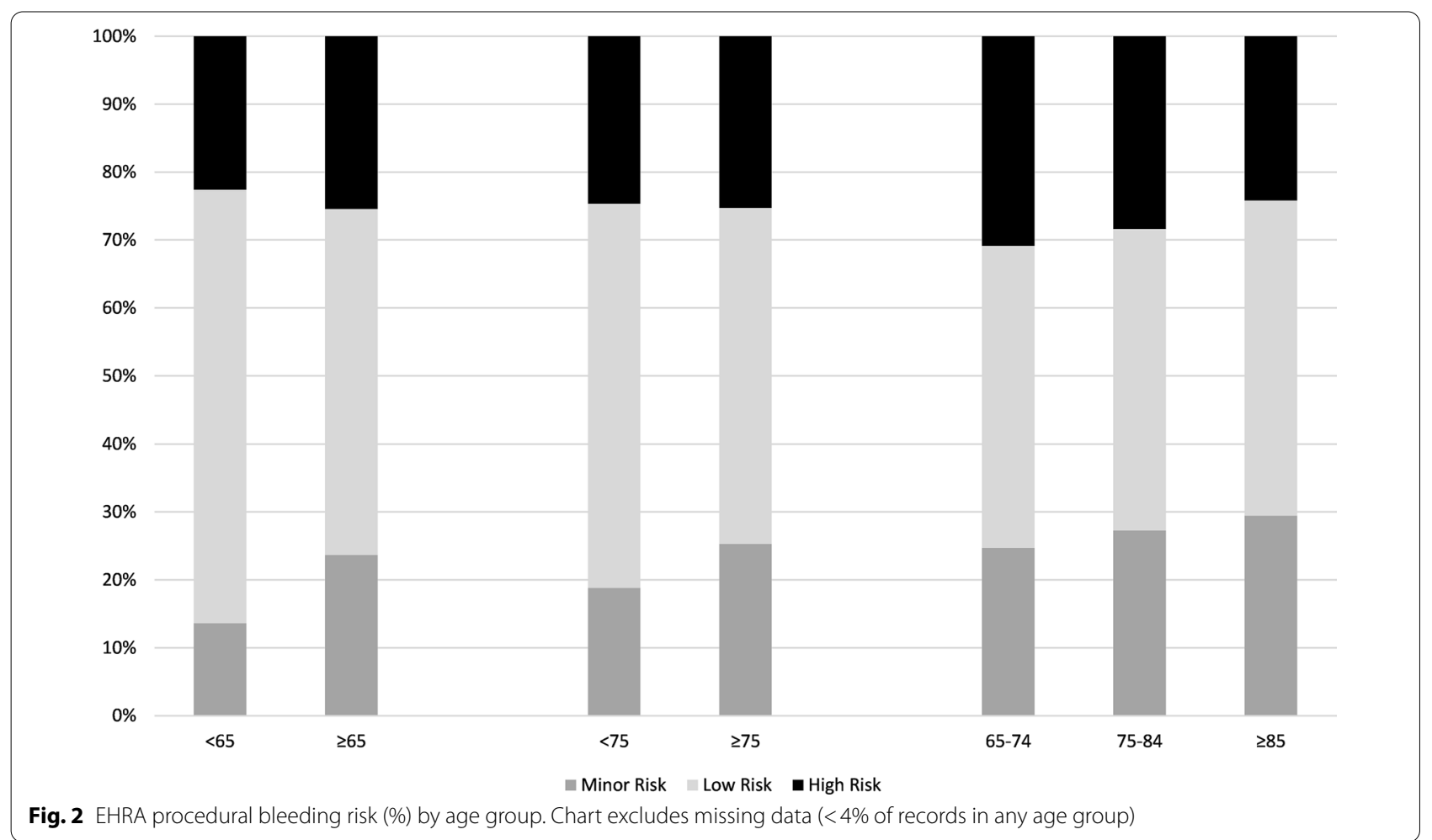

Table 4 Clinical outcomes by age group

\begin{tabular}{|c|c|c|c|c|c|c|c|c|}
\hline Outcome & $\begin{array}{l}\text { Age } \\
<65 \text { years }\end{array}$ & $\begin{array}{l}\text { Age } \\
\geq 65 \text { years }\end{array}$ & $\begin{array}{l}\text { Age } \\
<75 \text { years }\end{array}$ & $\begin{array}{l}\text { Age } \\
\geq 75 \text { years }\end{array}$ & $\begin{array}{l}\text { Age } \\
\geq 65-<75 \text { years }\end{array}$ & $\begin{array}{l}\text { Age } \\
\geq 75-<85 \text { years }\end{array}$ & $\begin{array}{l}\text { Age } \\
\geq 85 \text { years }\end{array}$ & Total \\
\hline Number of subjects & 280 & 1162 & 830 & 612 & 550 & 514 & 98 & 1442 \\
\hline All bleeding & $11(3.9 \%)$ & $39(3.4 \%)$ & $29(3.5 \%)$ & $21(3.4 \%)$ & $18(3.3 \%)$ & $17(3.3 \%)$ & $4(4.1 \%)$ & $50(3.5 \%)$ \\
\hline $\mathrm{MB}$ & $1(0.4 \%)$ & $5(0.4 \%)$ & $3(0.4 \%)$ & $3(0.5 \%)$ & $2(0.4 \%)$ & $3(0.6 \%)$ & 0 & $6(0.4 \%)$ \\
\hline MB or CRNMB & $2(0.7 \%)$ & $13(1.1 \%)$ & $11(1.3 \%)$ & $4(0.7 \%)$ & $9(1.6 \%)$ & $4(0.8 \%)$ & 0 & $15(1.0 \%)$ \\
\hline ACS & 0 & $1(0.1 \%)$ & $1(0.1 \%)$ & 0 & $1(0.2 \%)$ & 0 & 0 & $1(0.1 \%)$ \\
\hline Stroke & 0 & $5(0.4 \%)$ & $1(0.1 \%)$ & $4(0.7 \%)$ & $1(0.2 \%)$ & $3(0.6 \%)$ & $1(1.0 \%)$ & $5(0.3 \%)$ \\
\hline $\mathrm{TIA}$ & 0 & $1(0.1 \%)$ & 0 & $1(0.2 \%)$ & 0 & $1(0.2 \%)$ & 0 & $1(0.1 \%)$ \\
\hline VTE & 0 & $1(0.1 \%)$ & 0 & $1(0.2 \%)$ & 0 & $1(0.2 \%)$ & 0 & $1(0.1 \%)$ \\
\hline SEE & 0 & $1(0.1 \%)$ & 0 & $1(0.2 \%)$ & 0 & $1(0.2 \%)$ & 0 & $1(0.1 \%)$ \\
\hline CV mortality & 0 & $3(0.3 \%)$ & $1(0.1 \%)$ & $2(0.3 \%)$ & $1(0.2 \%)$ & $2(0.4 \%)$ & 0 & $3(0.2 \%)$ \\
\hline All-cause mortality & 0 & $9(0.8 \%)$ & $6(0.7 \%)$ & $3(0.5 \%)$ & $6(1.1 \%)$ & $2(0.4 \%)$ & $1(1.0 \%)$ & $9(0.6 \%)$ \\
\hline
\end{tabular}

rate of $0.35 \%$ and a $\mathrm{MB}$ rate of $1.62 \%$ in patients treated with dabigatran. The DRESDEN Registry [23] reported peri-procedural $\mathrm{MB}$ rates of $1.2 \%$ and cardiovascular event rates of $1 \%$ in a series of 863 procedures in patients who were mainly treated with rivaroxaban. Although different study designs, the event rates in EMIT and all these studies are similar. The four studies together indicate that oral anticoagulation when managed carefully is associated with a low incidence of major haemorrhagic and/or significant thromboembolic events.
Several studies have evaluated DOAC use in the elderly; however, many have not collected peri-procedural data. Halperin et al. [26], reporting the ROCKETAF comparison of rivaroxaban with VKA in patients with AF, noted increased thromboembolic (4.61 events/100 patient-years vs. 6.07 ) and $\mathrm{MB}$ rates (2.69 vs. 4.86$)$ in the patients aged $<75$ or $\geq 75$ years, respectively. The RE-LY study [27] evaluated patients randomized to dabigatran or warfarin. Thromboembolic rates (per patient-year) increased from $1.32 \%$ in subjects $<65$ years of age, to 


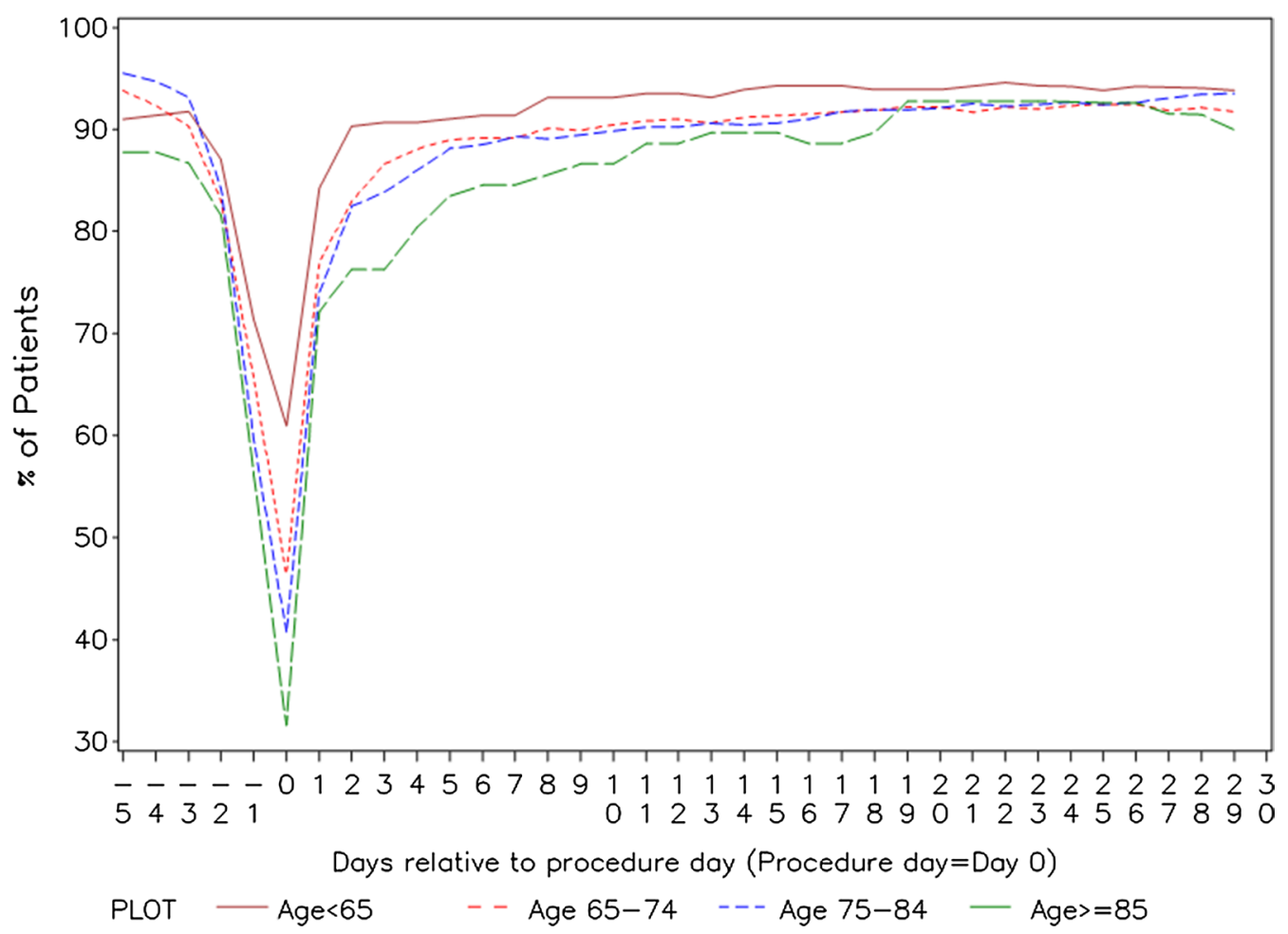

Fig. 3 Time course of edoxaban interruption

$1.95 \%$ in those aged $80-84$ years. The MB rate was $0.14 \%$ in subjects $<65$ years of age and $5.01 \%$ in those aged $80-84$ years. In patients with AF not undergoing procedures, the risk of stroke increases 1.5 -fold for each decade [28].

\section{Limitations of study}

One limitation of this study is a lack of a comparator arm and its restriction to one DOAC, although this study provides data on peri-procedural management of edoxaban for the first time. The much greater sample size required for a comparator would not have been feasible from a timing or economic perspective [29]. No attempt was made to evaluate the impact of geographical location or ethnicity. Subtle differences in outcome may exist between the various DOAC and/or be influenced by ethnic or geographic factors, although the pharmacodynamic characteristics of the FXa-inhibitors are rather similar and mainly depend on renal function.

To account for the challenges of data collection in a registry, patients were provided with memory aids to support data recall, data elements were reviewed at the patient level, and all critical events were centrally adjudicated. Offsetting any loss in quality because of missing data or lack of mechanisms to support compliance is the ability of an observational study to accurately reflect current clinical practice without external influence.

\section{Conclusions}

Detailed age-based subset analysis of the original EMIT data shows minimal differences in patient risk factors linked to age; however, management differed in the elderly. The overall rates of MB and CRNMB were low, and there were no clear age-related trends in incidence. However, the incidence of ischemic complications in the elderly trended higher than in the younger population. This difference is better explained by a longer duration of interruption (both pre- and post-procedural) in the elderly and very elderly, rather than differences in procedural risk, thus supporting the view that increasing age should not be a barrier to adequate anticoagulation [30]. Optimal management that balances thromboembolic and bleeding risk in the elderly is yet to be fully defined.

\section{Supplementary information}

Supplementary information accompanies this paper at https://doi. org/10.1186/s12872-020-01766-w.

Additional file 1. EMIT study Ethics Committees. 


\section{Abbreviations}

ACS: Acute coronary syndrome; AF: Atrial fibrillation; CRNMB: Clinically relevant non-major bleeding; DVT: Deep vein thrombosis; EMIT: Edoxaban management in diagnostic and therapeutic; ISTH: International Society of Thrombosis and Haemostasis; MB: Major bleeding; PE: Pulmonary embolism; SEE: Systemic embolic events; TIA: Transient ischemic attack.

\section{Acknowledgements}

This work was supported by Daiichi Sankyo, Inc. Assistance in editorial support for this manuscript was provided by QPS Consulting, LLC (Ashburn, VA, USA), and funded by Daiichi Sankyo, Inc. The authors are indebted to Dr. Robert Crozier and Dr. Wei Jiang for discussion and critical reading of this manuscript.

\section{Authors' contributions}

$\mathrm{MU}, \mathrm{CVH}, \mathrm{AS}, \mathrm{MS}, \mathrm{TV}, \mathrm{RW}, \mathrm{PC}$, and CC reviewed the data and wrote the paper. $J J$ and PL provided statistical analysis. All authors read and approved the final manuscript.

\section{Funding}

This research was funded by Daiichi Sankyo, Inc. The funding body played a role in the design of the study and collection, analysis, and interpretation of data and in writing the manuscript.

\section{Availability of data and materials}

The datasets generated and/or analysed during the current study are not publicly available because this study is sponsored by a pharmaceutical company and the raw data are proprietary, but they are available from the corresponding author on reasonable request.

\section{Code availability}

Not applicable.

\section{Ethics approval and consent to participate}

In all countries participating in the study, approval was obtained from a central Ethics Committee and several site-specific Ethics Committees. The study was conducted in accordance with the Declaration of Helsinki and with local Institutional Review Board approvals and was registered as NCT02950168. Please find the complete list of Ethics Committees that provided approval in the Additional file 1. Written informed consent was obtained from participants prior to enrolment.

\section{Consent for publication}

Not applicable: no identifiable subjects are described.

\section{Competing interests}

PC reports grants and personal fees from Daiichi Sankyo Europe and personal fees from Daiichi Sankyo Italy during the conduct of the study; personal fees from Boehringer Ingelheim, Bayer AG, and Pfizer/BMS; and non-financial support from the European Society of Cardiology and the Italian Cardiology Association outside the submitted work. $\mathrm{CvH}$ reports grants and personal fees from Daiichi Sankyo Europe and Daiichi Sankyo Germany during the conduct of the study; personal fees from Boehringer Ingelheim, Bayer AG, Pfizer GmbH, CSL Behring, NovoNordisk Pharma, Mitsubishi Pharma, Ferring GmbH, Biotest $\mathrm{GmbH}$, and Leo Pharma GmbH outside the submitted work; that he was mandated from the German Society of Anaesthesiology and Intensive Care Medicine to write the German Guideline on Preoperative Anaemia (published in April 2018); was part of the writing group of the Patient Blood Management Guideline in cardiac surgery on behalf of the European Society of Cardiothoracic Anaesthesiologists in conjunction with the European Society of Cardiothoracic Surgery (published in September 2017); and was mandated to take part in the writing group of the guideline on the Diagnostics and Treatment of Peripartum Haemorrhage of the Deutsche Gesellschaft für Gynäkologie und Geburtshilfe (published in March 2016). AS reports nothing to disclose. MS reports grants and personal fees from Daiichi Sankyo Europe and personal fees from Daiichi Sankyo UK during the conduct of the study. TV reports grants and personal fees from Daiichi Sankyo Europe; and personal fees from Daiichi Sankyo Be, Bayer, 367 Leo Pharma, and Boehringer Ingelheim during the conduct of the study. PL, CC, and MU are employees of Daiichi Sankyo. RW reports personal fees from Daiichi Sankyo, Inc., during the conduct of the study.

\section{Author details}

${ }^{1}$ Global Medical Affairs Specialty and Value Products, Daiichi Sankyo Inc., 211 Mt Airy Road, Basking Ridge, NJ 07920, USA. ${ }^{2}$ Department of Anaesthesia and Intensive Care Medicine, Emergency Medicine, and Pain Therapy, Vivantes Klinikum Im Friedrichshain, Landsberger Allee 49, 10249 Berlin, Germany. ${ }^{3}$ Hematology Department, University Hospital Vilaopó y Torrevieja, Alicante, Spain. ${ }^{4}$ William Harvey Research Institute, Barts Health NHS Trust, Charterhouse Square, London EC1M 6BQ, UK. ${ }^{5}$ Department of Cardiovascular Sciences, University Hospitals (UZ) Leuven, Leuven, Belgium. ${ }^{6}$ Daiichi Sankyo, Medical Affairs Europe, Munich, Germany. ${ }^{7}$ QPS Consulting, LLC, 19884 Naples Lakes Terrace, Ashburn, VA 20147, USA. ${ }^{8}$ Department of Cardiology, Polyclinic of Bari - Hospital, 70124 Bari, Italy.

Received: 26 August 2020 Accepted: 1 November 2020

Published online: 01 December 2020

\section{References}

1. Kirkwood TBL. Why and how are we living longer? Exp Physiol. 2017;102(9):1067-74.

2. Staerk L, Sherer JA, Ko D, Benjamin EJ, Helm RH. Atrial fibrillation: epidemiology, pathophysiology, and clinical outcomes. Circ Res. 2017:120(9):1501-17.

3. Klotz U. Pharmacokinetics and drug metabolism in the elderly. Drug Metab Rev. 2009:41(2):67-76.

4. Koren G, Nordon G, Radinsky K, Shalev V. Clinical pharmacology of old age. Expert Rev Clin Pharmacol. 2019;12(8):749-55.

5. Lee P, Regenbogen S, Gawande A. How many surgical procedures will Americans experience in an average lifetime? Evidence from three states. In: Poster P15 Massachusetts chapter of the American College of Surgeons. 2008 55th annual meeting. https://mcacs.org/abstracts/2008/ P15.cgi. Accessed 24 Jan 2020.

6. Chugh SS, Havmoeller R, Narayanan K, et al. Worldwide epidemiology of atrial fibrillation: a Global Burden of Disease 2010 study. Circulation. 2014;129:837-47

7. Baron TH, Kamath PS, McBane RD. Management of antithrombotic therapy in patients undergoing invasive procedures. N Engl J Med. 2013:368(22):2113-24.

8. Douketis JD, Spyropoulos AC, Duncan J, et al. Perioperative management of patients with atrial fibrillation receiving a direct oral anticoagulant. JAMA Int Med. 2019:179(11):1469-78.

9. Wolff A, Shantsila E, Lip GY, Lane DA. Impact of advanced age on management and prognosis in atrial fibrillation: insights from a populationbased study in general practice. Age Ageing. 2015;44:874-8.

10. Akao M, Chun YH, Esato $M$, et al. Inappropriate use of oral anticoagulants for patients with atrial fibrillation. Circ J. 2014;78:2166-72.

11. Patti G, Lucerna M, Pecen $L$, et al. Thromboembolic risk, bleeding outcomes and effect of different antithrombotic strategies in very elderly patients with atrial fibrillation: a sub-analysis from the PREFER in AF (prevention of thromboembolic events-European registry in atrial fibrillation). J Am Heart Assoc. 2017;6(7):e005657.

12. Colonna P, von Heymann C, Santamaria A, et al. Routine clinical practice in the periprocedural management of edoxaban therapy is associated with low risk of bleeding and thromboembolic complications: The prospective, observational, and multinational EMIT-AFNTE study. Clin Cardiol. 2020. https://doi.org/10.1002/clc.23379.

13. Colonna P, von Heymann C, Santamaria A, et al. Edoxaban management in diagnostic and therapeutic procedures (EMIT-AF/NTE)-trial design. Clin Cardiol. 2018;41(9):1123-9.

14. De Caterina R, Agnelli G, Laeis P, et al. The global edoxaban treatment in routine cliNical prActice (ETNA) noninterventional study program: rationale and design. Clin Cardiol. 2019;42(12):1147-54.

15. Schulman S, Angeras U, Bergqvist D, et al. Definition of major bleeding in clinical investigations of antihemostatic medicinal products in surgical patients. J Thromb Haemost. 2010;8(1):202-4.

16. Steffel J, Verhamme P, Potpara TS, et al. The 2018 European Heart Rhythm Association Practical Guide on the use of non-vitamin K antagonist oral anticoagulants in patients with atrial fibrillation. Eur Heart J. 2018;39(16):1330-93. 
17. Zhu W, He W, Guo L, et al. The HAS-BLED score for predicting major bleeding risk in anticoagulated patients with atrial fibrillation: a systematic review and meta-analysis. Clin Cardiol. 2015;38(9):555-61.

18. Gažová A, Leddy JJ, Rexová M, et al. Predictive value of CHA2DS2-VASC scores regarding the risk of stroke and all-cause mortality in patients with atrial fibrillation (CONSORT compliant). Medicine (Baltimore) 2019;98(31):e16560.

19. https://unstats.un.org/unsd/publication/SeriesM/SeriesM_74e.pdf. Accessed 22 Jan 2020

20. Guidance for Industry E7 Studies in Support of Special Populations: Geriatrics Questions and AnswersE7 FDA Guidance Document on Definition of Elderly current as of 2018 https://www.fda.gov/media/78220/downl oad. Retrieved on 27 Mar 2020.

21. Singh S, Bajorek B. Defining 'elderly' in clinical practice guidelines for pharmacotherapy. Pharm Pract. 2014;12(4):489.

22. Smith KB, Smith MS. Obesity statistics. Prim Care. 2016;43(1):121-35.

23. Beyer-Westendorf J, Gelbricht V, Forster K, et al. Peri-interventional management of novel oral anticoagulants in daily care: results from the prospective Dresden DOAC registry. Eur Heart J. 2014;35(28):1888-96.

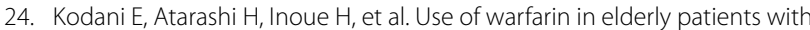
non-valvular atrial fibrillation-subanalysis of the J-RHYTHM Registry. Circ J. 2015;79(11):2345-52.

25. Healey JS, Eikelboom J, Douketis J, et al. Peri-procedural bleeding and thromboembolic events with dabigatran compared with warfarin: results from the randomized evaluation of long-term anticoagulation therapy (RE-LY) randomized trial. Circulation. 2012;126(3):343-8.

26. Halperin JL, Hankey GJ, Wojdyla DM, et al. Efficacy and safety of rivaroxaban compared with warfarin among elderly patients with nonvalvular atrial fibrillation in the Rivaroxaban Once Daily, Oral, Direct Factor Xa Inhibition Compared with Vitamin K Antagonism for Prevention of Stroke and Embolism Trial in Atrial Fibrillation (ROCKET AF). Circulation. 2014;130:138-46.

27. Lauw MN, Eikelboom JW, Coppens M, et al. Effects of dabigatran according to age in atrial fibrillation. Heart. 2017;103:1015-23.

28. Stroke Risk in Atrial Fibrillation Working Group. Independent predictors of stroke in patients with atrial fibrillation: a systematic review. Neurology. 2007:69(6):546-54.

29. Douketis JD, Spyropoulos AC, Kaatz S, et al. Perioperative bridging anticoagulation in patients with atrial fibrillation. N Engl J Med. 2015;373(9):823-33.

30. Kato ET, Goto S, Giugliano RP. Overview of oral antithrombotic treatment in elderly patients with atrial fibrillation. Ageing Res Rev. 2019;49:115-24.

\section{Publisher's Note}

Springer Nature remains neutral with regard to jurisdictional claims in published maps and institutional affiliations.
Ready to submit your research? Choose BMC and benefit from:

- fast, convenient online submission

- thorough peer review by experienced researchers in your field

- rapid publication on acceptance

- support for research data, including large and complex data types

- gold Open Access which fosters wider collaboration and increased citations

- maximum visibility for your research: over $100 \mathrm{M}$ website views per year

At BMC, research is always in progress.

Learn more biomedcentral.com/submissions 